\title{
Tamhinispora a new genus belongs to family Tubeufiaceae from the Western Ghats, India based on morphology and phylogenetic analysis
}

\section{Rajeshkumar KC ${ }^{*}$ and Sharma R}

National Fungal Culture Collection of India, MACS’ Agharkar Research Institute, Pune, Maharashtra, India

Rajeshkumar KC, Sharma R 2013 - Tamhinispora a new genus belongs to family Tubeufiaceae from the Western Ghats, India based on morphology and phylogenetic analysis. Mycosphere 4(2), 165-174, Doi 10.5943/mycosphere/4/2/2

A new genus and species, Tamhinispora indica, was collected on decaying Bambusa bambos culms from Tamhini Ghats, northern Western Ghats of Maharashtra. Morphologically, this new genus can be easily differentiated from similar genera like Ernakulamia, Pseudoacrodictys, Petrakia, Biconiosporium, Pseudopetrakia and Manoharachariella by having dark blackish brown, mostly ovoid or irregular, dictyoseptate conidia with apical appendages diverging or radiating from the conidial tip and intercalary, almost sessile conidiogenous cells in hyphae. Phylogenetic analysis using ITS and LSU sequences establish the placement of Tamhinispora in the family Tubeufiaceae; allied to dictyochlamydospore-forming or dark brown conidia-forming genera like Chlamydotubeufia and Helicoon.

Key words - anamorphic fungi - Ascomycota - dematiaceous - dictyoseptate - stauroconidium

\section{Article Information}

Received 10 January 2013

Accepted 31 January 2013

Published online 16 March 2013

*Corresponding author: Rajeshkumar KC - e-mail - rajeshfungi@ gmail.com

\section{Introduction}

The Western Ghats, a mega diversity hot spot situated in the southern west coast of the Indian Peninsula has a rich and diverse flora and fauna. The pristine natural forests, microhabitats, and tropical warm humid climate that prevail in the Western Ghats support many rare and new forms of fungi (Bhat \& Kendrick 1993, Rajeshkumar 2007). During 2010-2012, surveys were conducted to explore the microfungal diversity in natural forests of southern and northern Western Ghats (Rajeshkumar et al. 2011a, b, Rajeshkumar \& Singh 2012, Rajeshkumar et al. 2012). One of the survey in the bamboo dominating evergreen patch in the valley of the Tamhini Ghats resulted in the collection of a rare dematiaceous hyphomycete subsequently determined to be a new genus. The present study describes and illustrates this unusual dematiaceous, dictyoseptate, stauroconidium-forming hyphomycete collected from the Tamhini Ghats. 


\section{Methods}

\section{Isolates and morphology}

Conidia were isolated directly from the surface of a dead twig and observed under a Nikon binocular stereomicroscope (Model SMZ-1500 with Digi-CAM, Japan). Single conidial cultures were established on $2 \%$ potato dextrose agar plates (PDA; Crous et al. 2009). For morphotaxonomic studies and photomicrographs, Zeiss (AXIO Imager 2, Germany) and Olympus (Model CX-41, Japan) microscopes were used. Conidia and conidiophores were mounted in lactic acid cotton blue and measured using an ocular micrometer (and confirmed with software available with the Zeiss microscope), with 30 observations per structure. Culture colony characteristics were studied on two different media: $2 \%$ malt extract agar (MEA) and PDA (Crous et al. 2009). Colony colours were determined using Methuen Handbook of Colour (Kornerup \& Wanscher 1981). A herbarium specimen was deposited in the Ajrekar Mycological Herbarium (AMH), and the culture was accessioned and preserved at NFCCI; WDCM932, Agharkar Research Institute, Pune, India.

DNA extraction, Polymerase chain reaction (PCR) and Sequencing - Total DNA was extracted from cultures grown on PDA plates for 2 weeks at $25^{\circ} \mathrm{C}$, using the method of Aljanabi \& Martinez (1997). Fragments containing the region encoding the $28 \mathrm{~S}$ nrDNA (LSU) and ITS 1-5.8S nrDNA-ITS 2 (ITS) were amplified using primer pairs 5.8SR, LROR (Rehner \& Samuels 1994) and LR7 (Vilgalys \& Hester 1990) for LSU; ITS4 and ITS5 (White et al. 1990) for ITS. DNA amplification was performed in a $25 \mu 1$ reaction using $2 \mu \mathrm{l}$ of template DNA (25 ng), $1 \mathrm{U}$ of Taq DNA polymerase (Genei, Bangalore, India), $2.5 \mu$ of $10 \times$ Taq DNA polymerase buffer, $1 \mu \mathrm{l}$ of $200 \mu \mathrm{M}$ of each dNTPs (Genei, Bangalore, India), $1 \mu \mathrm{l}$ of 10 pmol primer, $\mathrm{H}_{2} \mathrm{O}$ (Sterile Ultra Pure Water, Sigma) to make up $25 \mu$. Amplification in an Eppendorf Mastercycler Gradient 5331 AG used the following parameters: $5 \mathrm{~min}$ at $95^{\circ} \mathrm{C} ; 30$ cycles of $1 \mathrm{~min}$ at $95^{\circ} \mathrm{C}, 1 \mathrm{~min}$ at $56^{\circ} \mathrm{C}$, and $1 \mathrm{~min}$ at $72^{\circ} \mathrm{C}$ for the ITS region amplification; and final $7 \mathrm{~min}$ extension step at $72^{\circ} \mathrm{C}$. DNA amplification of LSU followed the ITS conditions except for a $52^{\circ} \mathrm{C}$ annealing temperature. The PCR products were purified with an Axygen PCR cleanup kit (Axygen Scientific, CA, USA) and sequenced with the same primers using the BigDye Terminator v3.1 Cycle Sequencing Kit (Applied Biosystems, USA). The sequencing reactions were run on an ABI 3100 automated DNA sequence (Applied Biosystems, USA).

Sequence alignment and phylogenetic analysis - LSU and ITS sequences from Tamhinispora indica NFCCI 2924 were manually edited using Chromas Lite software (www.technelysium.com.au) and deposited in the NCBI Genbank DNA sequence database (ITS: KC469282, LSU: KC469283). They were also subjected to a BLAST search of the NCBI nucleotide database. For phylogenetic analysis, the sequences were aligned using Clustal W together with the homologous regions of ITS and LSU of closely related genera and species. For construction of phylogenetic tree, the matrix was analyzed using Neighbor-Joining method of Molecular Evolutionary Genetics Analysis (MEGA) software v5.0. (Tamura et al. 2011). The sequence alignment and phylogenetic tree are deposited in TreeBASE (http://purl.org/phylo/treebase/Phylows/study/T B2:S13794). Spencermartinsia viticola (A.J.L. Phillips \& J. Luque) A.J.L. Phillips, A. Alves $\&$ Crous (Phillips et al. 2008) belonging to family Botryosphaeriaceae was selected as out group.

\section{Results}

Tamhinispora Rajeshkumar \& Rahul Sharma gen. nov.

MycoBank MB803105

Differs from the allied genera in having dark blackish brown ovoid to irregular conidia with radiating or diverging apical appendages from conidial tip and almost sessile conidiogenous cells.

Colonies effuse, blackish brown to black, Mycelium mostly semi-immersed or immersed, single or interwoven, Stroma none, Setae and hypopodia absent, Conidiophores absent, Conidiogenous cells, semi-macronematous, unbranched, intercalary in hyphae, almost sessile. 
Mycosphere Doi 10.5943/mycosphere/4/2/2

Conidia solitary, dry, simple, mostly ovoid or irregular, dictyoseptate, smooth, young conidia pale to dark brown with or without appendages, mature conidia dark brown to blackish with apical appendages, Apical appendages rudimentary or well developed, arising from tip of conidia, diverging or radiating, pale to dark brown, septate, tip rounded.

Type species

Tamhinispora indica Rajeshkumar \& Rahul Sharma, sp. nov.

MycoBank 803106

Figs 1-19

Etymology - Genus named after the place of collection Tamhini Ghats and species named after the country where this fungus is native.

Colonies effuse, dark brown (6F4), blackish brown (6G8) to black, Conidia solitary, dry, simple, mostly ovoid or irregular, dark brown to blackish, dictyoseptate, paler towards tip when young, 54.5-108 × 34.5-50 $\mu \mathrm{m}$, smooth, Apical appendages 0-9, rudimentary or well developed, arising from tip of conidia, radiating, pale to dark brown, septate, 0-7 septa, 13.5-95 × 3.8-6.3 $\mu \mathrm{m}$.

Teleomorph - Unknown/Not observed.

Known distribution - found in the natural forests of northern Western Ghats.

Material examined - India, Maharashtra, Mulshi, Tamhini Ghats, on Bambusa bambos, 15 July 2012, Rajeshkumar $\mathrm{KC}$, holotype, AMH 9555 - ex-type culture in NFCCI 2924

Notes - The culture on MEA and PDA after 10 days at $25 \pm 2^{\circ} \mathrm{C}$, brownish grey $(6 \mathrm{~F} 2)$ to greyish brown (6E3) or blackish, slow growing, velutinous, $2-3 \mathrm{~mm}$ diam. after 60 days, centre becomes raised and dull reddish brown (8E8) after long incubation, reverse blackish, Sporulation not found in culture.

\section{Phylogenetic analyses}

Sequencing of the partial LSU gene of NFCCI 2924 resulted in 700 bp long sequence (KC469283) which in BLAST search showed maximum identity of $97 \%$ with Helicomyces macrofilamentosus

(HKUCC10235; AY849942.1), 96\% with H. roseus (BCC3381;
AY78732.1 and AFTOL-ID 1613; DQ678083.1), Chlamydotubeufia khunkornensis (MFLUCC10-0118; JN865190.1), Tubeufia amazonensis (ATCC42524; AY87938.1), Chlamydotubeufia huaikangplaensis (MFLUCC10-0926; JN865198.1), T. cerea (IFO9014; AY849964.1), T. paludosa CBS 120503; GU301877.1), 95\% with $T$. helicomyces (AFTOL-ID 1580; DQ767654.1), T. cylindrothecia (BCC3559; AY849965.1), Acanthostigma chiangmaiensis (MFLUCC100125; JN865197.1), Thaxteriellopsis lignicola (MFLUCC10-0123; JN865195.1) and 94\% with other members of family Tubeufiaceae. A phylogenetic was tree constructed using 22 additional sequences retrieved from Genbank belonging to 19 species of family Tubeufiaceae (Fig. 20). All 20 species including Tamhinispora indica clustered into four major clades. Tamhinispora indica was placed close to Helicomyces macrofilamentosus, Tubeufia cylindrothecia and Helicomyces roseus.

Sequencing of the ITS region of rDNA resulted in 570 bp long sequence (KC469282) which in BLASTn search showed maximum similarity of $90 \%$ with Tubeufia auratiella (voucher ANM 718; GQ856140.1), Helicoma violaceum (CBS 222.58; AY916469.1), Helicoma morganii (CBS 281.54; AY916468.1), Helicosporium panachaeum (CBS257.59; AY916471.1), 89\% with Helicosporium griseum CBS 961.69; AY916474.1), Helicomyces bellus (CBS 113542; AY916475.1), Helicosporium lumbricoides (JCM 9265; AY916476.1) and $88 \%$ with several species belonging to Helicosporium, Helicomyces and Acanthostigma. For phylogenetic analysis additional 25 sequences (21 species) belonging to family Tubeufiaceae were retrieved from Genbank and aligned with the sequence of Tamhinispora indica. A Neighbor-joining tree was constructed from this analysis (Fig. 21) in which Tubeufiaceae members formed four major clades. Tamhinispora indica was placed in the second clade along with Helicosporium panachaeum, Tubeufia aurantiella, Helicosporium griseum, Helicoma violaceum and $H$. morganii, which are morphologically quite dissimilar from the new fungus. 
Mycosphere Doi 10.5943/mycosphere/4/2/2

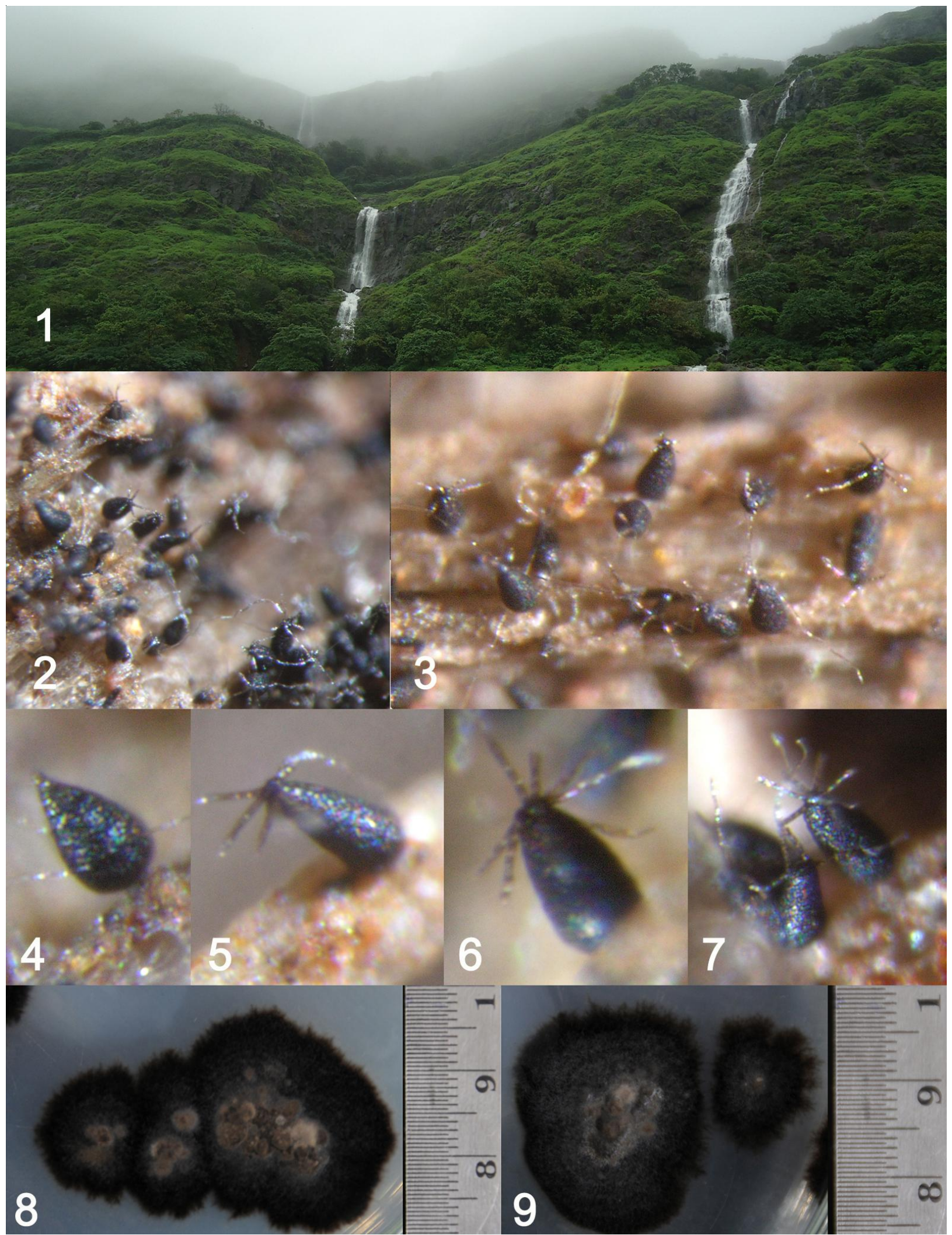

Figs 1-9 - Tamhinispora indica (holotype). 1 Habitat Tamhini Ghats. 2, 3 Habit on Bambusa bambos decaying twigs. 4-7 Mature conidia in nature with rudimentary or well developed apical appendages. 8, 9 Single conidial cultures on PDA after 60 days. 


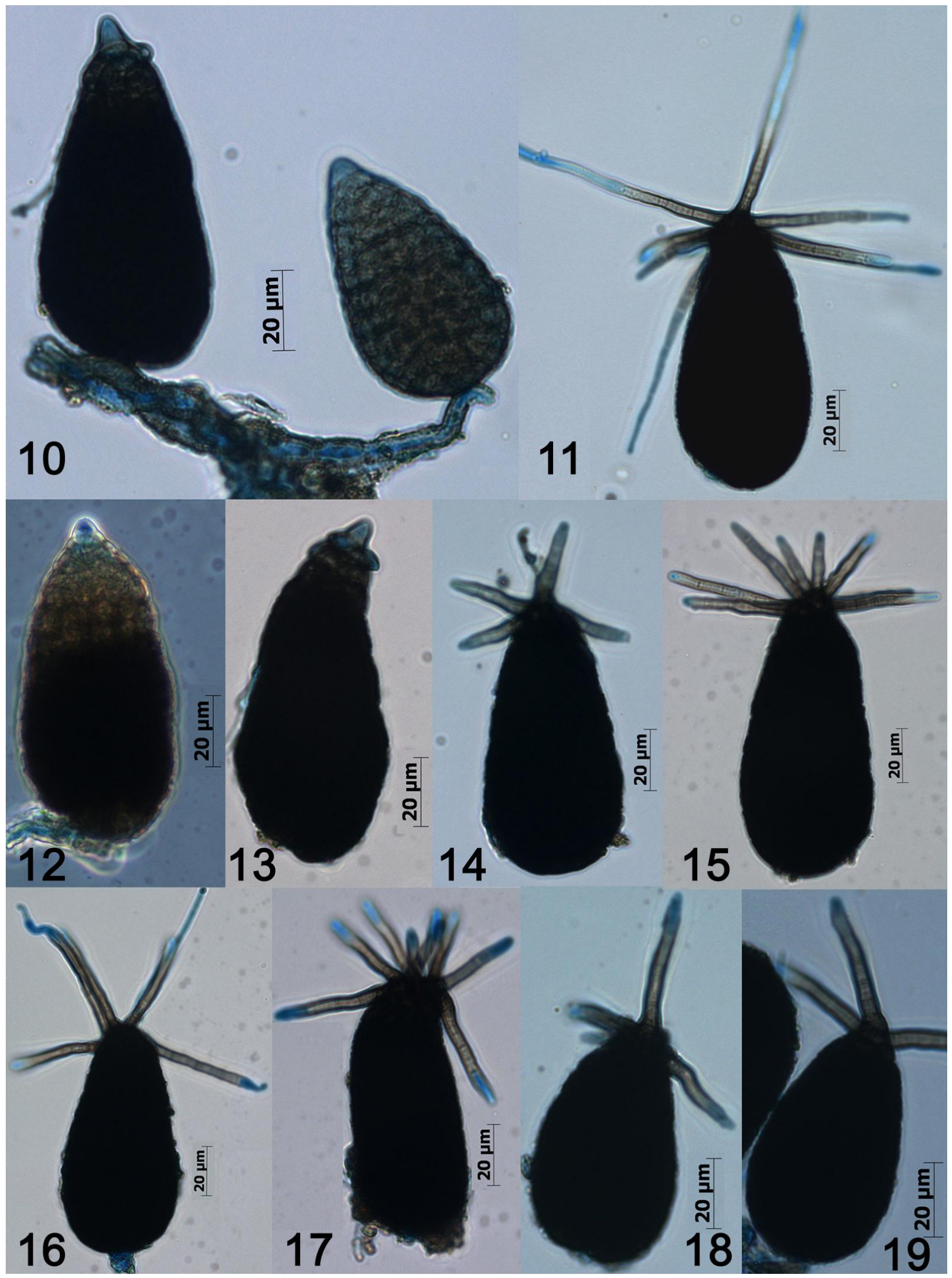

Figs 10-19-Tamhinispora indica (holotype). 10 Conidial development. 11 Mature conidia with apical appendages. 12-19 Variation in conidial size, shape and apical appendages. - Bars $=20 \mu \mathrm{m}$. 


\section{Discussion}

Considering the conidial morphology Tamhinispora can be classified under stauroconidium, body dictyoseptate with 3-5 radiating arms group (Seifert et al. 2011), which includes Ernakulamia Subram., Pseudoacrodictys W.A. Baker \& MorganJones and Petrakia Syd. \& P. Syd. Another similar group with dictyoseptate conidia, dark, paler horns or lobes includes Biconiosporium Bat. \& J.L. Bezzera, Pseudopetrakia M.B. Ellis and Manoharachariella Bagyan. N.K. Rao \& Kunwar (Seifert et al. 2011). The conidia in Tamhinispora are mostly ovoid and dark brownish black or black in nature with radiating apical appendages, which are septate, pale brown and arising from the conidial tip.

Tamhinispora is unique and distinct from the morpho-taxonomically similar genera like Ernakulamia, Pseudoacrodictys, Petrakia, Biconiosporium, Pseudopetrakia and Manoharachariella. Morphologically Ernakulamia is most allied to Tamhinispora; both genera have reduced intercalary conidiogenous cells, diverging or radiating appendages and dictyoseptate conidia. However, conidial shape and arrangement of apical septate appendages are different. Conidia in Tamhinispora are mostly ovoid and apical appendages arise from tip of conidia, whereas in Ernakulamia conidia are irregular in shape and apical appendages arise from different conidial cells (various loci) of upper part in conidium. Furthermore, conidiogenesis is monoblastic and conidial secession is rhexolytic in Tamhinispora, in contrast to monotretic and schizolytic in Ernakulamia. In Pseudoacrodictys, conidiophores are well developed, unbranched, brown with percurrent proliferations; similarly, the genus Petrakia has sporodochia/stromata and conidiophores that evidently differentiate both these genera from Tamhinispora. Biconiosporium also resembles Tamhinispora with both genera possessing intercalary, monoblastic conidiogenous cells in hyphae. In contrast, Biconiosporium is different by short, non-septate apical arms. However, apical appendages in Tamhinispora are well developed, septate and diverging or radiating from conidial tip. Pseudopetrakia has reduced branched or unbranched conidiophores which are absent in Tamhinispora; in addition
2-4 black, sharp apical spines are unique in Pseudopetrakia. In Manoharachariella, conidia are apiculate and tiered and never have apical appendages; similarly conidiophores are well developed and branched which is reduced to intercalary, monoblastic conidiogenous cells in Tamhinispora.

Phylogenetic analyses of isolate NFCCI 2924 established the placement of Tamhinispora in family Tubeufiaceae. The Tubeufiaceae sensu Barr (1979) includes the type genus Tubeufia and was placed under Pleosporales. Most taxa of Tubeufiaceae are saprobic on dead plant material, especially wood, fungi or scale insects (Barr 1980, Rossman 1987, Kodsueb et al. 2006, Promputtha \& Miller 2010, Sánchez \& Bianchinotti 2010). The Tubeufiaceae have been thoroughly studied and revised by several authors (Barr 1980, Rossman 1987, Kirk et al. 2001, Lumbsch \& Huhndorf 2010) and there was a recent morphological re-examination and phylogenetic placement of major taxa from Thailand (Boonmee et al. 2011). Boonmee et al. (2011) made a definite progress towards establishing the generic concepts in the Tubeufiaceae and defined five distinct genera based on morphology and molecular data and accepted a further 14 genera based on morphology. The anamorphs of Tubeufiaceae have been well studied and include, helicosporous, staurosporous or dictyosporous forms belonging to Annellospermosporella, Aquaphila, Araneomyces, Guelichia, Helicoma, Helicoon, Helicomyces, Helicosporium, Monodictys-like, Pendulispora, Peziotrichum, Tetracrium, Titaea and Xenosporium (Ellis 1971, 1976, Kirk et al. 2008, Hyde et al. 2011). Phylogenetic analysis of larger ribosomal subunit of Tamhinispora indica shows Chlamydotubeufia Boonmee \& K.D. Hyde (Boonmee et al. 2011) and Helicoon Morgan are close to Tamhinispora. Anamorphic states of both these genera form dark brown pigmented helicoids (in Helicoon) and dictyochlamydospores that somewhat resemble the conidia of the new genus. On the contrary, dark blackish brown, ovoid or irregular, dictyoseptate conidia with apical appendages radiating from the conidial tip is unique in Tamhinispora. Xenosporium Penz. \& Sacc. is another dictyosporous anamoph included in the 


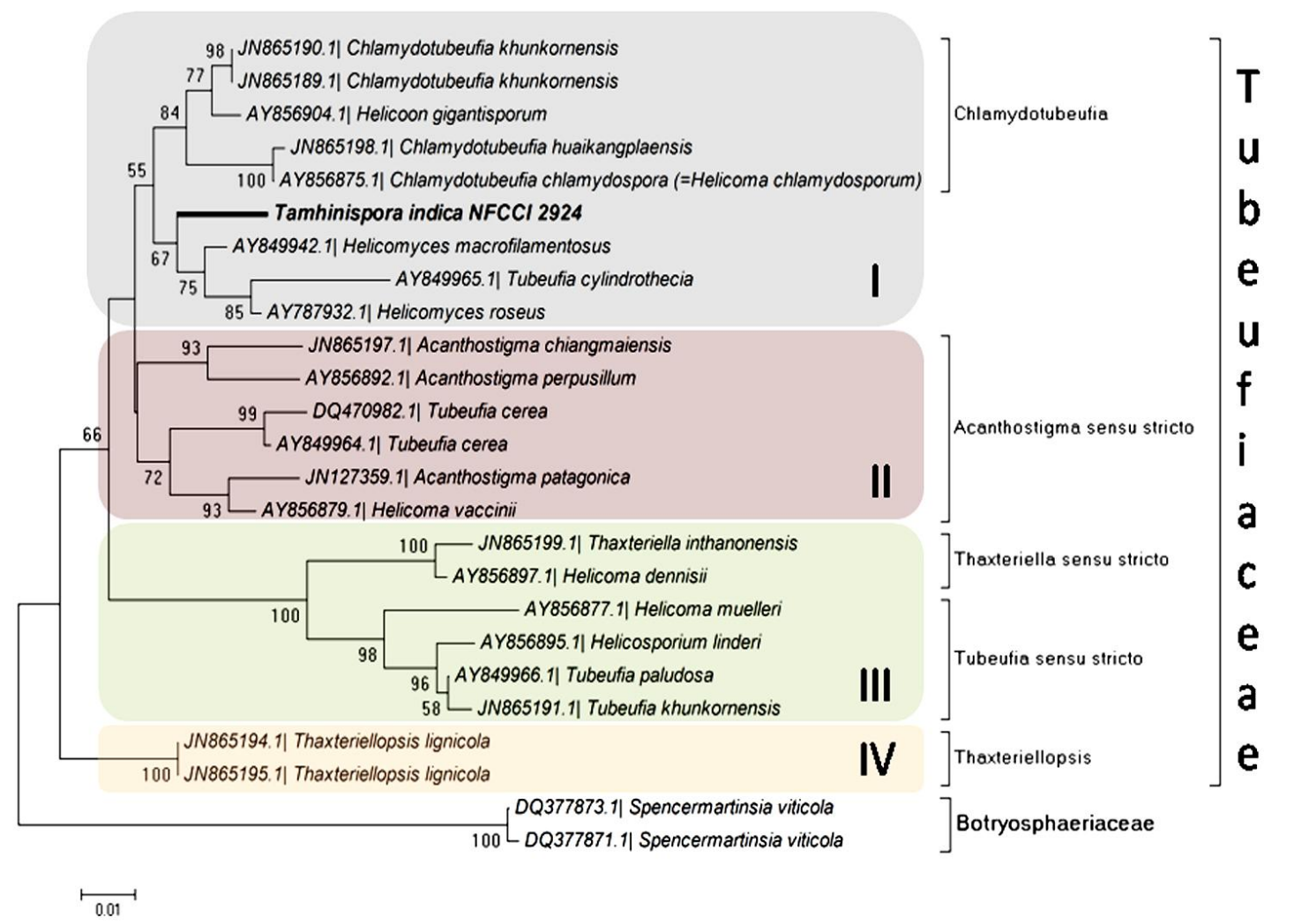

Fig 20 - Phylogenetic tree derived from aligned LSU sequences of Tamhinispora indica inferred using the Neighbor-Joining method based on the recent generic concepts of the Tubeufiaceae established by Boonmee et al. (2011). The percentage of replicate trees in which the associated taxa clustered together in the bootstrap test (1000 replicates) are shown next to the branches. The evolutionary distances were computed using the Maximum Composite Likelihood method. All positions containing gaps and missing data were eliminated from the dataset (Complete deletion option). There were a total of 448 positions in the final dataset. Phylogenetic analyses were conducted in MEGA4.

Tubeufiaceae (Kirk et al. 2008, Hyde et al. 2011). Thaxteriellopsis is the teleomoph for Xenosporium species (Index Fungorum). Boonmee et al. (2011) epitypified the type species of Thaxteriellopsis, T. lignicola Sivan., Panwar \& S.J. Kaur which forms a distinct clade in the phylogenetic tree and is justified as a genus distinct from Thaxteriella. Earlier studies by Subramanian \& Sekar (1982) stated that Thaxteriellopsis lignicola was associated with Moorella like anamorphs. However, the phylogenetic relation of Xenosporium to that of Thaxteriellopsis is yet to be resolved. Morphology of a Xenosporium species, $X$. ovatum has some resemblance with young conidia of Tamhinispora. However, the conidiophores are well developed and distinct to that of the new genus. In addition, septate pale brown conidial appendages are not seen in Xenosporium, which is mainly characterized based on the presence of zero to muriform septate secondary conidia.

Similar to that of Xenosporium, Monodictys-like anamorphs were also reported in the Tubeufiaceae (Seifert et al. 2011). This lineage is also yet to be resolved through a detailed exploration and phylogenetic analysis. Hyde et al. (2010), Vasilyeva \& Stephenson (2010) and Boonmee et al. (2011) emphasized the importance of recollection of generic types and epitypification using molecular phylogenetic data so as to progress further to define the generic boundaries in the family Tubeufiaceae. 


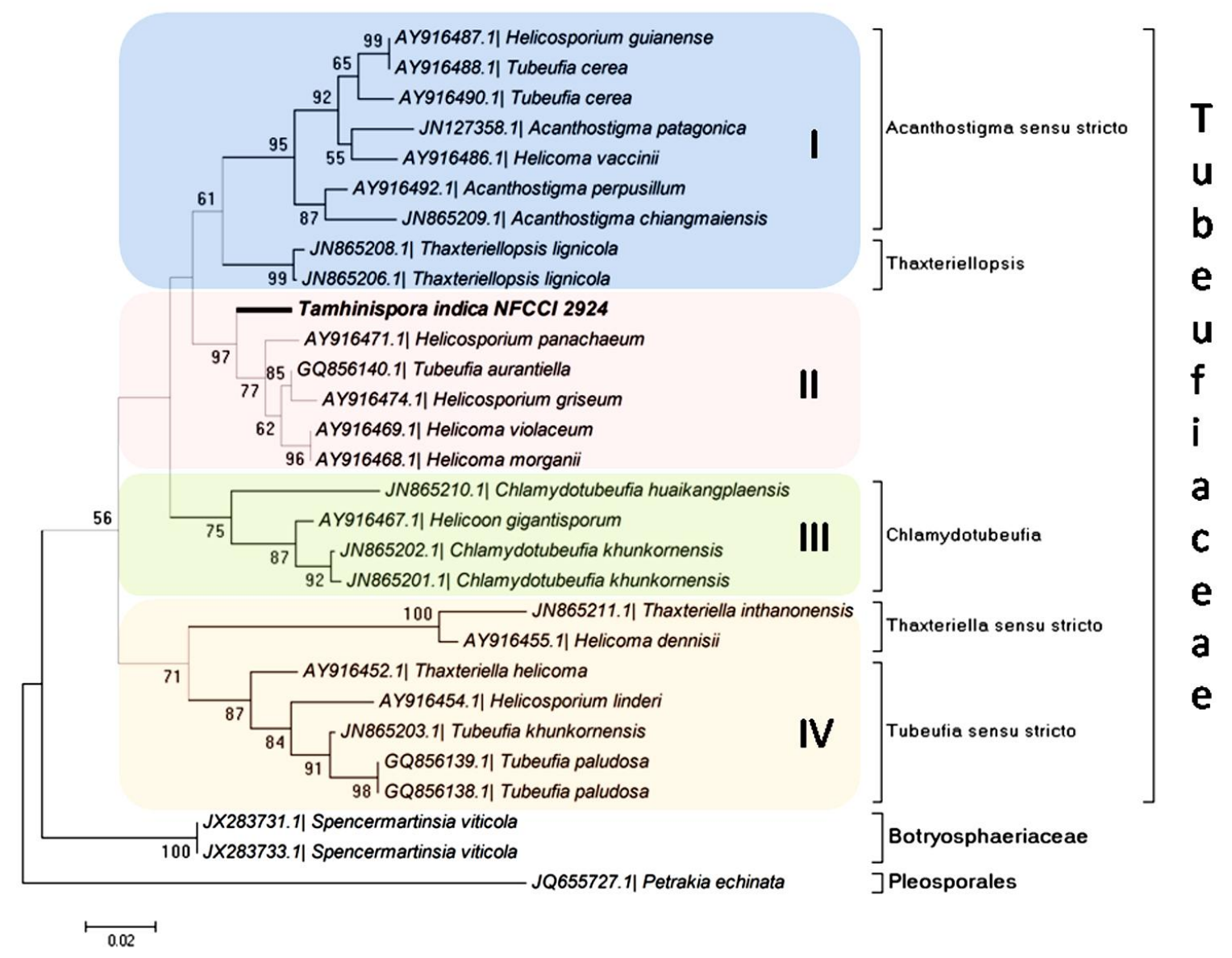

Fig 21 - Phylogenetic tree based on aligned ITS sequences of Tamhinispora indica and its closely allied species in Tubeufiaceae was performed based on the recent generic concepts of the Tubeufiaceae established by Boonmee et al. (2011) using the Neighbor-Joining method. The optimal tree with the sum of branch length $=0.77996294$ is shown. The percentage of replicate trees in which the associated taxa clustered together in the bootstrap test (1000 replicates) are shown next to the branches. The evolutionary distances were computed using the Maximum Composite Likelihood method and are in the units of the number of base substitutions per site. All positions containing gaps and missing data were eliminated from the dataset (Complete deletion option). There were a total of 268 positions in the final dataset. Phylogenetic analyses were conducted in MEGA4.

\section{Acknowledgements}

We are indebted to Eric McKenzie (Landcare Research, Auckland, New Zealand) for commenting on this manuscript. RKC thanks Prof. Pedro Crous for his valuable advice and suggestions. Thanks are also due to the Department of Science and Technology (DST), Government of India, New Delhi for providing financial support for setting up the National Facility for Culture Collection of Fungi (No. SP/SO/PS-55/2005) at Agharkar Research Institute, Pune, India and the Director, ARI for providing facility.

\section{References}

Aljanabi SM, Martinez I. 1997 - Universal and rapid salt-extraction of high quality genomic DNA for PCR-based techniques. Nucleic Acids Research 25(22), 4692-4693.

Barr ME. 1979 - A classification of Loculoascomycetes. Mycologia 71, 935-957.

Barr ME. 1980 - On the family Tubeufiaceae (Pleosporales). Mycotaxon 12, 137167. 
Bhat DJ, Kendrick B. 1993 - Twenty-five new conidial fungi from the Western Ghats and the Andaman Islands (India). Mycotaxon 49, 19-90.

Boonmee S, Zhang Y, Chomnunti P, Chukeatirote E, Tsui CKM, Bahkali AH, Hyde KD. 2011 - Revision of lignicolous Tubeufiaceae based on morphological re-examination and phylogenetic analysis. Fungal Diversity 51, 63-102.

Crous PW, Verkley GJM, Groenewald JZ, Samson RA (eds). 2009 - Fungal Biodiversity. CBS Laboratory Manual Series. Centraalbureau voor Schimmelcultures, Utrecht, Netherlands.

Ellis MB. 1971 - Dematiaceous hyphomycetes. CMI, Kew, UK. 608 p.

Ellis MB. 1976 - More dematiaceous hyphomycetes. CMI, Kew, UK. 507 p.

Hyde KD, McKenzie EHC, Ko Ko TW. 2011 Towards incorporating anamorphic fungi in a natural classificationchecklist and notes for 2010. Mycosphere 2, 1-88.

Hyde KD, Chomnunti P, Crous P, Groenewald J, Damm U, Ko Ko TW, Shivas R, Summerell B, Tan Y. 2010 - A case for re-inventory of Australia's plant pathogens. Persoonia 25, 50-60.

Kirk PM, Cannon PF, David JC, Stalpers JA. 2001 - Ainsworth \& Bisby`s Dictionary of the Fungi, 9th edn. CABI, Wallingford.

Kirk PM, Cannon PF, Minter DW, Stalpers JA. 2008 - Ainsworth \& Bisby`s Dictionary of the Fungi, 10th edn. CABI, Wallingford.

Kodsueb R, Jeewon R, Vijaykrishna D, McKenzie EHC, Lumyong P, Lumyong S, Hyde KD. 2006 - Systematic revision of Tubeufiaceae based on morphological and molecular data. Fungal Diversity 21, 105-130.

Kornerup A, Wanscher JH. 1981 - Methuen Handbook of Colour, 3rd ed. London, Methuen. 282 p.

Lumbsch HT, Huhndorf SM. (eds.) $2010-$ Outline of Ascomycota - 2009. Myconet 14, 1-64.

Phillips AJL, Alves A, Pennycook SR, Johnston PR, Ramaley A, Akulov A,
Crous PW. 2008 - Resolving the phylogenetic and taxonomic status of dark-spored teleomorph genera in the Botryosphaeriaceae. Persoonia 21, 2955.

Promputtha I, Miller AN. 2010 - Three new species of Acanthostigma (Tubeufiaceae, Dothideomycetes) from Great Smoky Mountains National Park. Mycologia 102, 574-587.

Rajeshkumar KC. 2007 - Diversity of plant pathogenic fungi in natural forests in the Western Ghats, India. Ph.D thesis, FRI University, Dehradun, India. 201 p.

Rajeshkumar KC, Singh SK. 2012 Manoharachariella indica sp. nov. from the Western Ghats, India. Mycotaxon 120, 43-48.

Rajeshkumar KC, Kajale S, Sutar SA, Singh SK. 2012 - Ellisembia karadkensis sp. nov. from the Western Ghats, India. Mycotax on 121, 181-186.

Rajeshkumar KC, Hepat RP, Gaikwad SB, Singh SK. 2011a - Pilidiella crousii sp. nov. from northern Western Ghats, India. Mycotaxon 115, 155-162. http://dx.doi.org/10.5248/115.155

Rajeshkumar KC, Sharma R, Hepat RP, Swami SV, Singh PN, Singh SK. 2011b Morphology and molecular studies on Pseudocercospora kamalii sp. nov. a foliar pathogen on Terminalia from India. Mycotaxon 117, 227-237. http://dx.doi.org/10.5248/117.227

Rehner SA, Samuels GJ. 1994 - Taxonomy and phylogeny of Gliocladium analysed from nuclear large subunit ribosomal DNA sequences. Mycological Research 98, 625-634.

Rossman AY. 1987 - The Tubeufiaceae and similar Loculoascomycetes. Mycological Papers 157, 1-71.

Sánchez RM, Bianchinotti MV. 2010 - New records in the Tubeufiaceae from Andean Patagonian forests of Argentina. Mycotaxon 11, 131-141.

Seifert K, Morgan-Jones G, Gams W, Kendrick B. $2011-$ The Genera of Hyphomycetes. CBS Biodiversity Series 9, 1-997.

Subramanian CV, Sekar G. 1982 - Thaxteriellopsis lignicola and its Moorella 
Mycosphere Doi 10.5943/mycosphere/4/2/2

anamorphs. Proceedings of Indian Academy of Sciences, Section B 91(1), $1-7$.

Tamura K, Peterson D, Peterson N, Stecher G, Nei M, and Kumar S (2011) MEGA5:

Molecular evolutionary genetics analysis using maximum likelihood, evolutionary distance, and maximum parsimony methods. Molecular Biology and Evolution 28, 2731-2739.

Vasilyeva LN, Stephenson SL. 2010 - The problems of traditional and phylogenetic taxonomy of fungi. Mycosphere 1, $45-51$.
Vilgalys R, Hester M. 1990 - Rapid genetic identification and mapping of enzymatically amplified ribosomal DNA from several Cryptococcus species. Journal of Bacteriology 172, 4238-4246.

White TJ, Bruns T, Lee J, Taylor J. 1990 Amplification and direct sequencing of fungal ribosomal RNA genes for phylogenetics. 315-322. In: Innis MA et al. (eds). PCR Protocols: a guide to methods and applications. Academic Press, San Diego. 